\title{
Colaboración entre centros públicos de investigación para el desarrollo regional: un análisis de caso en Aguascalientes, México
}

\section{Collaboration between public research centers for regional development: a case analysis in Aguascalientes, Mexico}

doi: https://doi.org// 0.32870/

eees.v27i77.7054

\section{Resumen}

Este artículo examina el contexto económico, social y político en el que surge un proyecto estratégico de colaboración basado en el modelo de la triple hélice para impulsar el desarrollo regional. Se toma como ejemplo la creación de un esfuerzo de colaboración entre centros públicos de investigación para desarrollar cadenas de proveeduría para la industria automotriz y de autopartes. Se utiliza el caso del proceso de reación del Centro de Innovación y Transferencia Tecnológica de Aguascalientes para el Sector Automotriz (CITTAA), en Aguascalientes, México. El análisis, de tipo descriptivo, hace énfasis en el tiempo que tomó configurar la propuesta, la poca duración que significa un sexenio para la meta de impulsar el desarrollo económico regional, $y$ las dificultades que presenta establecer $y$ promover la colaboración articulada entre los actores de una triple hélice.

Palabras clave: centros públicos de investigación, desarrollo regional, Aguascalientes, modelo de la triple hélice, México.
María Guadalupe Serna Pérez

\begin{abstract}
This article examines the economic, social and political context in which a strategic collaborative project based on the Triple Helix model to boost regional development emerges. The creation of a collaborative effort between public research centers to develop supply chains for the automotive and auto parts industry is taken as an example. It is used the case of the process of creation of the Center of Innovation and Technological Transfer of Aguascalientes for the Automotive Sector (CITTAA), in Aguascalientes, Mexico. The descriptive analysis emphasizes the time it took to set up the proposal, the short duration of a six-year term for the goal of promoting regional economic development, and the difficulties of establishing and promoting articulated collaboration between the actors of a triple helix.
\end{abstract}

Keywords: Public research centers, regional development, Aguascalientes, Tiple Helix model, Mexico.

\footnotetext{
-Profesora-Investigadora del Instituto de Investigaciones Dr. José María Luis Mora (Instituto Mora), México. ORCID: https://orcid.org/0000-0002-7895-959I

gserna@institutomora.edu.mx

Fecha de recepción: 09 de mayo de 2018. Fecha de aceptación: 24 de junio de 2019.
} 


\section{Introducción}

La transformación del estado de Aguascalientes (México) y el inicio de su proceso de industrialización tuvieron lugar en la década de los ochenta del siglo xx, enlazados a la propuesta del Gobierno federal para la integración y fortalecimiento de regiones en el país. El Gobierno de la entidad logró una articulación que impulsó su desarrollo económico, al contar con fondos para consolidar proyectos que llevaron a Aguascalientes a formar parte de la red del Tratado de Libre Comercio de América del Norte (TLCAN). Sin embargo, los embates económicos y las crisis recurrentes de inicios del nuevo milenio impactaron fuertemente en el desarrollo de la entidad, por lo que en 2010 se empezaron a replantear, de nueva cuenta, las alternativas para impulsar su desarrollo.

Dado el complejo panorama nacional que se presentaba a inicios de la década del 2010, la opción a nivel estatal para superar la crisis económica fue impulsar la competitividad regional en el marco del Plan Sexenal de Desarrollo 2010-2016 (PSD) del estado, que definió los parámetros para dicho fin. Dicho PSD tenía características particulares, ya que había sido delineado bajo la premisa de impulsar la sociedad del conocimiento ${ }^{1}$ como la clave para la innovación y la mejora de la competitividad regional.

I. El concepto de sociedad del conocimiento no tiene una definición unívoca y no hay un acuerdo general sobre su empleo. De acuerdo con la discusión planteada por León Olivé (2005), en la actualidad se refiere sobre todo a aquellos rasgos novedosos manifestados en el entorno social a partir de la segunda mitad del siglo $x x$ que han conducido al rápido incremento en el ritmo de creación, acumulación, distribución y aprovechamiento de la información y del conocimiento producido en un entorno global. Por lo mismo, el concepto se aplica principalmente al vertiginoso desarrollo de tecnologías que ha hecho posible ese crecimiento, particularmente las tecnologías de la información y la comunicación (TIC), y que tiene como consecuencia principal una serie de transformaciones en las relaciones sociales, económicas y culturales debidas a la aplicación del conocimiento y al impacto de esas tecnologías en la vida cotidiana. Como nunca antes, se atestigua la incorporación en las prácticas personales y colectivas de instrumentos y conocimientos que son producto de desarrollos científicos y tecnológicos cada vez más

\section{4}


De acuerdo con el nuevo equipo de Gobierno en el estado, iniciado en 2010, para superar la crisis se requería de estrategias específicas. De las cinco estrategias incluidas en el PSD para lograr el progreso económico integral, la tercera fue la conformación de la sociedad del conocimiento (Gobierno del estado de Aguascalientes, 2011a, p. 12). Para los efectos del plan, esta consistía en

facilitar la generación e intercambio del conocimiento, a través de programas que permitan a la sociedad satisfacer su necesidad de desarrollo, así como ayudar a los distintos sectores que la conforman a generar crecimiento económico a través de la innovación, desarrollo tecnológico e investigación científica. (Gobierno del estado de Aguascalientes, 20Ila, p. 57)

Para lograr esa sociedad del conocimiento en Aguascalientes, era necesario a su vez conformar el Estado del conocimiento -esto a través de la garantía de acceso a las tecnologías de la información y la comunicación (TIC) para toda la población-, impulsar el talento y propiciar "la implementación de sistemas para la innovación y desarrollo de sectores estratégicos" (Gobierno del estado de Aguascalientes, 2011a, pp. 56-58), eso último mediante la creación de infraestructura de investigación y desarrollo e incremento del producto interno bruto (PIB) de $0.35 \%$ a $1.0 \%$. Resulta interesante que esta misma perspectiva fuera incluida posteriormente en el Plan Nacional de Desarrollo 2012-

recientes. El conocimiento se ha vuelto un producto susceptible de apropiarse, comprarse y venderse. Se trata, entonces de una sociedad cuyas formas de organización de la economía, la educación y la cultura están íntimamente asociadas al desarrollo científico y tecnológico, y que son diferentes de las que se conocieron en la última mitad del siglo xx. Los Gobiernos, grupos empresariales y organismos internacionales suelen usar el concepto para referirse a una sociedad, todavía en construcción, que se basa en este nuevo modelo. Para una discusión más amplia, ver: Olivé (2005) y Castells (1999). En el caso concreto de este texto, el concepto a que se hace referencia es el que está inserto en el PSD 2010-2016 del Gobierno del estado de Aguascalientes (20l la).

Sociedad No.77 
2018 (PND), realizado por el entonces entrante Gobierno federal. Finalmente, como cierre de su sexenio, en mayo de 2016, el gobernador emitió la Ley de Ciencia, Tecnología, Innovación y Sociedad del Conocimiento para el Estado de Aguascalientes.

Consecuente con su programa, la primera acción del nuevo Gobierno, en enero de 2011, fue crear el Instituto de Desarrollo para la Sociedad del Conocimiento del Estado de Aguascalientes (IDSCEA), un organismo público descentralizado, con personalidad jurídica, dependiente del Ejecutivo estatal, cuyo objetivo sería "generar, con el acuerdo y colaboración de todos los sectores, la transformación de las capacidades de la población para crear una sociedad del conocimiento, que integre plenamente la cultura digital al desarrollo incluyente, económico, social y humano" (Periódico oficial del estado de Aguascalientes, 2011, pp. 2-9). Desde el instituto, se trabajaría en colaboración con instituciones públicas y privadas en acciones para conformar, construir y desarrollar la sociedad del conocimiento en el estado, de una forma incluyente y extendida a todos los ámbitos (Periódico oficial del estado de Aguascalientes, 2011, pp. 2-9). Más aún, se trabajaría para que la entidad fuera la sede de la sociedad del conocimiento.

En el marco de la creación de infraestructura de investigación y desarrollo de la entidad, el programa Fondos Mixtos (FOMIX) $^{2}$ se dio a la tarea de incrementar en el mismo periodo 2010-2016 la demanda de proyectos que estarían financiados con aportaciones federales y estatales para fomentar la innovación e impulsar la competitividad a nivel estatal. Uno de estos proyectos, en el rubro de estratégico, es el que se analiza en este artículo: la creación del Centro de Inno-

2. Los FomIX, programa iniciado en $200 \mathrm{I}$, son un instrumento de apoyo integrado por aportaciones estatales o municipales, y del Gobierno federal a través del Conacyt. Forman parte del Programa Presupuestario (PP) S278 Fomento Regional de las Capacidades Científicas Tecnológicas y de Innovación.

\section{6}


vación y Transferencia Tecnológica de Aguascalientes para el Sector Automotriz (CITTAA), posteriormente incorporado a la figura de consorcios de investigación propuesta por el Consejo Nacional de Ciencia y Tecnología (Conacyt). El objetivo de la demanda emitida por el Gobierno estatal fue fortalecer la infraestructura para la cadena automotriz y el desarrollo de la industria electrónica y de Tic, uno de los sectores clave de la entidad, como ya se dijo, para lo que se destinaron setenta y cuatro millones de pesos, el monto más importante que se ha dado en la historia de los FOMIX en Aguascalientes.

Conocer y analizar el contexto que precedió a esta decisión gubernamental, las acciones que acompañaron la estructuración del proyecto del CITTAA y el proceso seguido para su realización son asuntos de interés sociológico. Para ello, se vuelve pertinente examinar el contexto económico, político y social que prevalecía en Aguascalientes de fines del siglo $\mathrm{xx}$ a inicios del xxi para que se configurara el panorama que dio paso a la decisión de conformar y desarrollar la sociedad del conocimiento para contribuir a innovar y mejorar la competitividad.

\section{I.Aspectos contextuales y teóricos de la creación} del centro. El modelo de la triple hélice

El establecimiento de la postura oficial para la creación de la sociedad del conocimiento en la entidad servía de marco, como ya se adelantó, para proyectos que demandaban la participación de diversos sectores. Para el caso concreto del CITTAA, se requería la participación de la academia, vía los centros públicos de investigación (CPI) con trabajo en colaboración entre disciplinas ${ }^{3}$ e instituciones de edu-

3. Como se expondrá más adelante, la propuesta ganadora del proyecto del CITTAA fue presentada por el Centro de Investigaciones Ópticas (cıo) pero, para 
cación superior (IES) con el Gobierno estatal -que definía la demanda a realizar- y el sector empresarial, todo con miras a mejorar la competitividad y contribuir al desarrollo económico de la región.

Se trataba, como se expresó desde el Conacyt, de generar una nueva forma de trabajo de constante colaboración, a la que ciertamente los actores involucrados no estaban acostumbrados. En términos conceptuales, se aludía específicamente a poner en marcha el modelo de la triple hélice, que en el caso de México no tenía experiencias de ejercicio.

A diferencia de los modelos de desarrollo económico schumpeterianos, basados en la innovación como creadora de riqueza y en los que la empresa se ubicaba como el lugar que generaba la innovación tecnológica, el modelo de la triple hélice, concebido por Etzkowitz y Ledesdorff (1997), es sociológico, analiza la innovación y funciona como una guía para diseñar políticas en dicha área. Sus creadores lo formularon como un modelo en espiral de innovación que ofrece la posibilidad de captar, a lo largo del proceso, la manera para capitalizar el conocimiento que se adquiere por este y las posibles relaciones entre los puntos que lo conforman (Etzkowitz, 2002).

"La triple hélice expresa la relación universidad-industria-Gobierno como una relación entre iguales, relativamente independientes de esferas institucionales que se traslapan y toman el papel de las otras" (Etzkowitz, 2002, p. 3). Esta definición implica que la universidad toma un lugar central en el proceso previsto por el modelo.

El modelo sugiere una forma de promover la innovación y aduce razones que justifican y legitiman las decisiones políticas que se tomen en esa materia. Para el caso de México,

su desarrollo y puesta en marcha, se incorporaron a este once CPI más. Se trató de un proyecto cuyo reto inicial era lograr trabajar en conjunto y de forma colaborativa interdisciplinaria para luego hacer lo mismo con los otros dos sectores, el gubernamental y el empresariado. 
el modelo ofrece la posibilidad de analizar las interacciones que tienen lugar entre los tres actores que lo integran, universidad/CPI, Gobierno y empresa, este último como el lugar donde "germina el potencial para el conocimiento innovador, los recursos económicos y las posibilidades de mercado, así como las normas e incentivos de las políticas públicas de innovación" (González de la Fe, 2009, p. 740).

Se trata de un modelo innovador de convergencia de las mencionadas tres esferas, donde, hay que tener presente, cada una puede asumir el papel de la otra en distintos momentos, y que considera que "Estas relaciones triádicas están surgiendo a partir de diferentes puntos institucionales de partida en diversos lugares del mundo, pero con el propósito común de estimular el desarrollo económico basado en el conocimiento" (Etzkowitz, 2002, p. 3).

El modelo de la triple hélice facilita estudiar las experiencias exitosas que se tienen en el campo de la innovación, pues, como ya se dijo, explora la forma en que interactúan todos los actores a lo largo del proceso. De acuerdo con González de la Fe (2009), "los sistemas de innovación son el resultado de las interacciones en los intersticios de los tres subsistemas implicados" (p. 743). Su elemento central, la innovación, ofrece ventajas competitivas para las empresas y los centros de investigación científica y tecnológica al ser la base para crear riqueza y lograr el desarrollo económico (Etzkowitz y Leydesdorff, 2000), especialmente en una economía basada en el conocimiento.

Para el caso de América Latina, región en la que se incluye México, lo que ha sucedido es que la industria y la universidad/CPI han estado separadas una de la otra, y ha sido sólo la academia quien, en ocasiones, se relaciona con el sector gubernamental. De ello se desprende que el modelo de la triple hélice sea percibido más bien como un modelo normativo, cuyo interés es el esfuerzo de lograr un cambio 
dirigido y una mejora en las expectativas de innovación (Etskowitz, 2002, p. 8).

Por tanto, el reto de echar a andar el modelo de la triple hélice en México, en contextos donde esto ha sucedido poco o en los que no se tienen antecedentes acerca del qué y el cómo, resulta grande, pero también lleno de aprendizajes. La propuesta de los creadores del modelo es que en el proceso de aprendizaje este supone, en primer lugar, que los actores tienen que familiarizarse entre ellos y con sus respectivas formas de actuar. Posteriormente, en una segunda fase, deben involucrarse en la formulación de propuestas para iniciar procesos de colaboración y, más adelante, lograr impulsar el desarrollo económico vía la innovación.

Ahora bien, la decisión de analizar el proceso de creación del CITTAA a partir del modelo de la triple hélice obedece al hecho de que en la información recabada sobre dicho proceso se hizo evidente que para el Gobierno estatal, en la figura de los funcionarios del IDSCEA, se había expresado la puesta en marcha de ese mismo modelo en la creación del centro. Se consideraba que era la mejor opción para fomentar la sociedad del conocimiento que el plan gubernamental buscaba.

No obstante, la aplicación del modelo ha derivado en un proceso complicado de interacciones, más o menos esperable en un contexto donde este ejercicio de colaboración entre tres actores no era frecuente, lo que aunque no significa que dicha colaboración no sea posible, sí implica que esta puede llevar tiempo para lograrse.

\section{Desarrollo y organización del estudio}

La exposición realizada en este artículo está dividida en tres apartados. El primero es una apretada síntesis del proceso de industrialización de Aguascalientes de fines del siglo xx a inicios del xxI, que permite observar lo que sucedió en dicha entidad como efecto de la severa crisis

\section{0}


económica que enfrentó el país en esos años. El segundo se enfoca en la propuesta del PSD 2010-2016 y su preocupación por impulsar la sociedad del conocimiento en la entidad mediante el empleo de los instrumentos gubernamentales diseñados para apoyar el desarrollo regional. En el tercero, se describen y analizan la manera en que se ha procedido a estructurar el CITTAA y los logros y retos que han enfrentado los actores del proceso.

Cuando se analizan procesos, como en el presente caso, la metodología más adecuada es la cualitativa, pues permite poner en conjunción las distintas vertientes que el proceso analizado tiene y las rutas que sigue. Además, se emplea como estrategia el estudio de caso.

Si bien, como apunta Stake (2013), no todos los estudios de caso son cualitativos, para algunos paradigmas como los holísticos esta no es una elección metodológica, sino del objeto de estudio, en este caso, analizar un proceso. El interés, entonces, no es aportar datos, sino plasmar cómo se llevan a cabo las articulaciones en las que intervienen diversos actores en los distintos momentos y fases del proceso. Esto requiere trabajar con distintas fuentes, tanto documentales como provenientes de verbalizaciones y reflexiones de los actores involucrados, refiriéndose con esto último a entrevistas semiestructuradas.

Para esta investigación, se consultaron materiales del Instituto Nacional de Estadística y Geografía (INEGI), como censos y encuestas, al igual que la documentación generada por las convocatorias de los proyectos FOMIX en Aguascalientes, emitidas entre 2010 y 2016, así como documentos elaborados por el Conacyt relacionados con la política científica en México y la forma en que se planteó su articulación a distintos niveles. Se realizaron recorridos de área para conocer la ubicación y distribución de los CPI e IEs en Aguascalientes, así como de los distintos parques industriales y clusters con distintas especialidades. 
También, se llevaron a cabo observaciones no participantes en dos reuniones (entre enero y marzo de 2017) a las que se asistió por invitación y que fueron convocadas por los distintos actores involucrados en el proyecto del CITTAA. Estas permitieron conocer la manera en que se ponía en marcha la agenda de trabajo entre los funcionarios del Gobierno estatal y los administradores de los CPI asentados en Aguascalientes, vinculados con el proyecto.

Igualmente, se realizaron catorce entrevistas a profundidad entre los meses de enero y agosto de 2017, periodo que correspondió con los primeros meses de arranque de un nuevo Gobierno estatal, por lo que los funcionarios estaban dedicados a familiarizarse con la información y formas de operación de sus nuevas responsabilidades, a pesar de lo cual hubo una gran receptividad para atender las preocupaciones del estudio.

Del conjunto de entrevistas, dos correspondieron a funcionarios del IDSCEA, aunque en el caso del titular de la Secretaría de Desarrollo Económico (SEDEC) solamente se logró una muy breve conversación, debido a su complicada agenda. Seis entrevistas se realizaron a personal en posiciones directivas y administrativas de los CPI del estado, una a un directivo de una de las universidades tecnológicas de la entidad, y cinco a empresarios o líderes de cámaras empresariales y clusters de la industria automotriz y de la electrónica.

El objetivo de dichas entrevistas fue cubrir la mayor parte del espectro y las distintas ópticas que los actores tenían sobre el CITTAA. La estancia de la autora del estudio en el Centro de Investigación e Innovación en Tecnologías de la Información y Comunicación (INFOTEC) de Aguascalientes, de enero a agosto de 2017 como investigadora en sabático, permitió una constante interacción y cercanía con dichos actores clave.

En referencia a las reuniones y discusiones realizadas para la puesta en marcha del CITTAA, esta investigación 
concluyó en septiembre de 2017. Sin embargo, es importante mencionar que para diciembre de 2018, de acuerdo con el informe del Conacyt, el consorcio se encontraba en la fase de instalación, esto es, la construcción de sus espacios y talleres. ${ }^{4}$ Las siguientes fases del proceso serían el inicio de operaciones, equipamiento de las áreas, avanzar en la consolidación de vínculos con los sectores productivos, atraerlos al consorcio, trabajar de manera intensa con el Gobierno estatal, analizar y concretar las rutas a seguir, así como la atracción de empresas para contribuir al desarrollo regional. Cuando el estudio terminó, ya había retrasos con relación a la calendarización planteada para el resto de las fases.

\section{Despegue y retroceso del proceso de industrialización}

En los años ochenta, el estado mexicano de Aguascalientes había aprovechado la inversión federal disponible para desarrollar proyectos de infraestructura, lo que impulsó un proceso de industrialización orientado a la exportación que significó para la entidad incrementar sus posibilidades de atraer inversión externa (Salmerón Castro y Serna Pérez, 2000, p. 49) y, con ello, configurar a su ciudad capital como parte de la red integradora del TLCAN (Camacho Sandoval, 2010). Para los años noventa, la entidad habría sufrido una trasformación radical y dejado atrás la vocación agrícola que le había caracterizado, y entonces el sector manufacturero era estratégico pues aportaba casi un tercio del producto bruto estatal (Gobierno del estado de Aguascalientes, 1996, p. 21).

El sector manufacturero estaba conformado por la industria textil y del vestido, la automotriz y de autopartes, la metalmecánica, la electrónica y la de alimentos y bebidas. La textil y del vestido, integrada por unas trescientas empresas, destacaba en importancia con exportaciones de diversas

4. Este hecho ya no se constató en campo. Ver: https://www.conacyt.gob.mx/ index.php/consorcios 
prendas hacia Estados Unidos, Canadá y el resto de América Latina (Gobierno del estado de Aguascalientes, 1996, p. 23).

En el caso de la automotriz y de autopartes, esta se había consolidado especialmente después de la llegada de la armadora Nissan, en 1982, que a mediados de los noventa había ampliado sus instalaciones y logrado atraer inversión extranjera (Gobierno del estado de Aguascalientes, 1996, p. 24), si bien proveniente básicamente de empresas japonesas de autopartes.

La competidora directa de la industria automotriz, por número de empleos, era la metalmecánica, con más de 6000 trabajadores, frente a 7000 de la automotriz, y que contribuía con el $6.5 \%$ del valor de la producción manufacturera. Esta industria vendía al mercado nacional y exportaba directamente a Japón, Estados Unidos y Canadá (Gobierno del estado de Aguascalientes, 1996, p. 23).

La industria electrónica, por su parte, estaba integrada por fabricantes de microcomponentes, semiconductores y equipos de fotocopiado y también era muy dinámica y aportaba el 19\% del valor de la manufactura (Gobierno del estado de Aguascalientes, 1996, p. 27).

En resumen, sin duda, se había conseguido impulsar un proceso de industrialización diversificado y un entorno económico planificado en donde Aguascalientes era ya una pieza clave en el corredor industrial, posición que se vio reforzada "con la ampliación de la red carretera a nivel nacional y regional" (Camacho Sandoval, 2010, p. 49).

A fines del siglo xx, se había logrado atraer capital externo a la industria automotriz y de autopartes de la entidad, y se había vinculado a las grandes empresas locales textiles y del vestido con maquiladoras. Sin embargo, la administración gubernamental no había contemplado el diseño de futuras cadenas de proveeduría local.

En el caso de los micro y pequeños empresarios, estos externaban con frecuencia su inconformidad y desacuerdo 
frente a lo que sucedía: desde su perspectiva, las grandes empresas de capital internacional habían gozado de enormes privilegios para operar, lo que contrastaba con la desatención que ellos habían recibido. Estas expresiones de inconformidad fueron mal manejadas por la administración gubernamental. Adicionalmente, se había acentuado la diferenciación social, pues los ingresos medios y altos se habían concentrado en una proporción muy menor de la población, lo que generaba una base cada vez más amplia de trabajadores de bajos ingresos (Padilla, Gutiérrez, y López, 2015).

Derivado de esto, en 1998, a fines del sexenio en turno, se registró un cambio radical en el ámbito político y la gubernatura pasó por primera vez en la historia a manos del Partido Acción Nacional (PAN), en la figura de Felipe González González, un empresario local. ${ }^{5}$ En términos del Gobierno central, de corte priista, esto significó que sus decisiones no tuvieran eco alguno a nivel local.

Los efectos de esta situación se dieron en el corto plazo y vinieron acompañados de nuevas perspectivas sobre las fortalezas y debilidades de la entidad y las políticas sectoriales que se debían impulsar en ella. Para el 2000, el estado contaba con casi un millón de habitantes, su dinámica de crecimiento era buena y había atraído población, por lo que su saldo migratorio era positivo. No obstante, en una economía orientada a las manufacturas, la población aún no tenía el perfil requerido para satisfacer las necesidades del sector productivo, de ahí la necesidad de atender a la formación de capital humano calificado.

La propuesta del entonces nuevo Gobierno panista se enfocó en fortalecer e impulsar la productividad y las cadenas locales para insumos y bienes intermedios, primero en

5. En Aguascalientes, las decisiones tomadas desde el Gobierno central habían sido obedecidas sexenio tras sexenio, lo que no sucedió en las elecciones de 1998. Explicar el porqué de esta fractura tan severa no es el propósito de este texto, aunque ha sido un tema de análisis para algunos. Véanse: Franco Ruiz Esparza y Reyes Rodríguez (2005) y Camacho Sandoval (200I).

Sociedad No.77 
el sector agropecuario y luego en los otros sectores productivos. Con esto, se intentaba responder a las demandas del sector empresarial de la entidad, para lo que se fomentaron programas para el desarrollo de proveedores y se procuró promover una vinculación eficaz entre las IES y los CPI para impulsar el desarrollo tecnológico.

En el sexenio 2004-2010, el Gobierno panista, representado por Luis Armando Reynoso Femat, se orientó a la consolidación y modernización del empresariado en general mediante la creación de fondos estatales y el aprovechamiento de los provenientes del sector federal. En el mismo periodo, se amplió la oferta educativa, y en 2009 la entidad contaba ya con treinta y tres IES, entre ellas el Centro Universitario de las Artes del Instituto Cultural de Aguascalientes, la Universidad Politécnica, la Tecnológica, y otras privadas, como el campus Aguascalientes del Instituto Tecnológico y de Estudios Superiores de Monterrey (ITESM), así como tres CPI: el Centro de Tecnología Avanzada (CIATEQ), el Centro de Investigación en Matemáticas (CIMAT) y el Centro de Investigaciones en Óptica (CIO), que habían llegado a Aguascalientes invitados por el Gobierno de Otto Granados Roldán (1992-1998) - que les había proporcionado terrenos- para abrir sus sedes.

También, en las mismas fechas se contaba con el Instituto Nacional de Investigaciones Forestales, Agrícolas y Pecuarias (INIFAP), de larga existencia en el estado, y otros centros de carácter privado. Todas estas instituciones permitieron la creación de nuevas carreras y la actualización de otras enfocadas al desarrollo de capacidades de emprendimiento y de software avanzado, pues las grandes empresas requerían de servicios de tipo corporativo.

Justo en este periodo, como parte del Programa para el Desarrollo de Industrias de Software (PRosofT), de la Secretaría de Economía, se instalaron veintidós empresas dedicadas al desarrollo tecnológico y la innovación, 
que generaron cerca de 10000 empleos. En el caso de la industria electrónica, de la que la entidad era uno de los tres grandes polos de desarrollo del país, se registraron mejoras en la exportación de hardware y software y equipos sofisticados para el sector médico, al igual que servicios para las grandes empresas globales (Gobierno del estado de Aguascalientes, 2011a, pp. 22-24). En esa etapa, se creó el parque Tecnopolo 1-Pocitos, en que se instalaron estas empresas, y se construyeron las instalaciones del ITESM Aguascalientes y del Consejo de Ciencia y Tecnología del Estado de Aguascalientes (CONCYTEA).

Para mejorar la productividad, se trabajó en colaboración con la Organización para la Cooperación y el Desarrollo Económicos (OCDE) y el Banco Mundial, a partir de una política basada en clusters. ${ }^{6}$ En 2009 , la entidad contaba ya con diez de estos, tres de los cuales se orientaban al desarrollo de las tecnologías y la innovación (Gobierno del estado de Aguascalientes, 2011a).

A pesar de todos estos esfuerzos, el panorama no mejoró: al cierre de empresas lo acompañó un deterioro del nivel de vida de la población, así como la migración hacia otras entidades, algo antes impensable en Aguascalientes. El crecimiento económico fue muy menor, y la entidad dejó de ser parte de las más competitivas del país.

Entre 2004 y 2009, la entidad había mantenido su crecimiento económico a una tasa anual del 3.08\%, superior a la media nacional de 1.88\% (Gobierno del estado de Aguascalientes, 2011a, p. 21). Sin embargo, la severa crisis económica que impactó el mundo en 2008 también golpeó a Aguascalientes: la industria maquiladora disminuyó su actividad y hubo pérdida de una gran cantidad de empleos. La inversión extranjera directa, que había ido al alza, había

6. Los clusters, de acuerdo con la OCDE,"son una red de producción de empresas interdependientes, vinculadas entre sí en una cadena de producción que añade valor" (Organización para la Cooperación y el Desarrollo Económicos, 1999, p. 85).

Sociedad No.77 
empezado a perder dinamismo desde el 2005 (Padilla, Gutiérrez, y López, 2015, p. 6).

En el ámbito político, a unos meses del cambio de Gobierno en 2010, surgieron impugnaciones del Partido Revolucionario Institucional (PRI) y el PAN hacia Martín Orozco Sandoval, expresidente municipal de la ciudad capital y uno de los precandidatos del PAN a la gubernatura. Este tuvo que enfrentar un procedimiento administrativo que lo obligó a recurrir a la Justicia federal, en un problema que se extendió varios meses y que creó un ambiente de constantes enfrentamientos. Finalmente, la contienda electoral de ese 2010 se dio entre Martín Orozco Sandoval y Carlos Lozano de la Torre, ${ }^{7}$ quien había contribuido sustancialmente a delinear lo que sería el desarrollo industrial y económico en la entidad desde mediados de los setenta y había sido tres veces secretario de Desarrollo Económico. Carlos Lozano de la Torre resultó ganador con un margen del 4\%, por lo que el PRI regresó a la gubernatura (Medina Torres y Hernández Olmo, 2012) en unas elecciones particularmente reñidas.

\section{La ruta del desarrollo económico: hacia la sociedad del conocimiento}

Como ya se discutió, en el Plan Sexenal 2010-2016, presentado por el Gobierno de Carlos Lozano de la Torre,

7. Carlos Lozano de la Torre fue el responsable de crear la Oficina de Promoción Industrial, en el Gobierno de José Refugio Esparza Reyes, a mediados de los setenta. Continuó en el cargo con Rodolfo Landeros Gallegos, quien la elevó al rango de Secretaría de Promoción Industrial y Comercial. De nueva cuenta en 1992, con Otto Granados Roldán, Carlos Lozano de la Torre se desempeñó como secretario de Desarrollo Económico y creó la Comisión Estatal de Desarrollo Económico y Comercio Exterior (CEDECE). Para 2004, ocupó también la cartera de secretario de Desarrollo Económico en Zacatecas y se desempeñó como senador de la república entre 2006 y 2009, puesto en el que también formó parte de la Comisión de Comercio y Fomento Industrial. Como ingeniero industrial y administrador, especialista en planeación y con una amplia experiencia, estaba al tanto de las discusiones sobre innovación y, por ende, del tema en boga de la sociedad del conocimiento.

\section{8}


el desarrollo económico se enfocó en el diseño de políticas para la generación de empleo y en perfilar estrategias para impulsar el crecimiento (Gobierno del estado de Aguascalientes, 2011a, pp. 17-20). El desarrollo de la sociedad del conocimiento se concibió en el plan como motor clave para impulsar la competitividad, y junto con empleo, seguridad, calidad de vida y estado verde se planteó como una de las políticas conductoras transversales.

Mejorar la competitividad era una preocupación en dicho sexenio porque Aguascalientes había ocupado el segundo lugar en el índice respectivo a fines del siglo xx y en el periodo 2008-2010, de acuerdo con el Instituto Mexicano para la Competitividad (IMCO) (2012), pasó de la sexta a la octava posición. Sin embargo, reposicionarse llevaría algunos años, pues todavía en 2012 la entidad se ubicó en el décimo segundo lugar (Bernal y Mungaray Lagarda, 2017, p. 182).

Como ya se discutió al inicio de este artículo, en enero de 2011 el gobernador Carlos Lozano de la Torre creó el IDSCEA en sustitución del CONCYTEA, "como órgano público descentralizado con personalidad jurídica y patrimonio propio, para crear un mapa de habilidades para focalizar estratégicamente las unidades económicas actuales y futuras, [para] que sean congruentes con el entorno de trabajo" (Periódico oficial del estado de Aguascalientes, 2011, p. 2).

El objetivo del IDSCEA se planteó como:

Desarrollar planes y programas, así como políticas para promover la integración de empresas, Gobierno, universidades, centros de investigación y ciudadanos en áreas específicas como el diseño agrícola, la biotecnología, el diseño automotriz, el diseño mecánico, el diseño tecnológico, las tecnologías de la información, así como una cultura digital entre la población. (Periódico oficial del estado de Aguascalientes, 20 I I, p.6) 
Su primer director general fue Pedro Rivas Godoy, y en 2013 lo sustituyó el maestro Rafael Urzúa Macías, exrector de la Universidad Autónoma de Aguascalientes (UAA), quien diseñó y puso en marcha las políticas en materia de ciencia, tecnología e innovación. Desde el IDSCEA, se convocó a la participación de los otros dos actores clave que conformaron la ya señalada triple hélice: los CPI e IES y el sector empresarial.

Para ese entonces, la entidad contaba con una planta, aunque reducida, de investigadores pertenecientes al Sistema Nacional de Investigadores (SNI), que era necesario incrementar. También era urgente formar capital humano técnico y científico que llevara a cabo innovaciones en la industria automotriz y el desarrollo de software y energías alternativas. Asimismo se planteó incrementar el PIB destinado a ciencia y tecnología del .35\% a 1\%, así como fortalecer los Fomix y los programas de Estímulos a la Innovación (PEI) y sectoriales (Gobierno del estado de Aguascalientes, 2011b, p. 44).

También, se atendió al fortalecimiento de la infraestructura de investigación y desarrollo tecnológico mediante la invitación a otros CPI para que abrieran una sede en la entidad, así como se buscó contar con un parque para la investigación y el desarrollo tecnológico, todo esto bajo la responsabilidad del IDSCEA.

Ya en 2009, el gobernador Luis Armando Reynoso Femat había realizado gestiones con el Centro de Investigación y Docencia Económicas (CIDE) y el INFOTEC ${ }^{8}$ para que abrieran una sede en la entidad. Las mismas fueron inauguradas en 2011 y 2013 por el entonces gobernador Carlos Lozano de la

8. Aparentemente, la llegada de estas sedes de centros de investigación se vio envuelta en una discusión con investigadores de la UAA relacionada con el destino de los fondos del CONCYTEA, pues se adelantaba que la universidad se quedaría sin apoyos para investigación. Aunque se menciona este incidente, se señala que es necesario ampliar las fuentes e información relacionadas con él.Véase, por ejemplo: http://www.lja.mx/20 I0/07/muestran-indignacion-academicos-de-la-uaa-por-actuacion-del-concytea/ 
Torre en terrenos que se les proporcionaron en el entonces nuevo parque Tecnopolo2.

En 2015, Centro Geo ${ }^{9}$ formó parte del Laboratorio Nacional de Políticas Públicas en el CIDE, con lo que la entidad contó ya con seis CPI. En el mismo Tecnopolo2 se construirían las instalaciones del CITTAA, uno de los proyectos estratégicos del sexenio 2010-2016 y al que se le ha destinado el monto más importante en las convocatorias FOMIX de Aguascalientes.

De acuerdo con la información recabada, la academia y el sector gubernamental percibieron al CITTAA como la expresión concreta del impulso a la innovación y la mejora de la competitividad en Aguascalientes y la región. Para lograrlo, se requirió alinear todas las piezas del engranaje, entre ellas el fortalecimiento de los clusters, ${ }^{10}$ pues de los diez que operaban entonces solamente el de la industria mueblera había logrado un encadenamiento para funcionar como tal (Díaz Torres y Feria Cruz, 2008).

Frente a esta situación, se necesitaba certificar a las empresas y formar recursos humanos altamente capacitados, para lo que se promovió la vinculación de aquellas con las instituciones educativas y se echaron a andar proyectos formativos (Gobierno del estado de Aguascalientes, 2011b, p. 44).

Otro punto a resolver en el corto plazo fue la necesidad de contar con una proveeduría local competitiva, asunto que por años seguía sin atender, aun cuando era clave para vincular a las unidades económicas locales con la gran empresa (Gobierno del estado de Aguascalientes, 2011b, p. 38).

El Aguascalientes de 2010 era muy distinto al de los noventa: la zona metropolitana de la capital se había

9. Centro Geo inició la construcción de su sede a mediados de 2017, también en el parque Tecnopolo2.

I0. En este artículo, no se ha explorado la relación que se tiene en los agrupamientos tipo cluster, donde las empresas están asociadas por mutuo acuerdo, ni se analizaron los nexos que estas sostienen con las cámaras empresariales.

Sociedad No.77 
extendido a los municipios de Jesús María y San Francisco de los Romos, con una importante infraestructura para la movilidad interior que facilitaba la comunicación, así como una excelente red carretera.

Los sectores económicos habían cambiado en importancia: ahora el de los servicios era prioritario y aportaba el 53\% del PIB, el de las manufacturas hacía lo propio con un $42 \%$, y el agropecuario, otrora importante, apenas representaba el 6\% (esto último un tema preocupante, ya que la autosuficiencia alimentaria no estaba garantizada). ${ }^{11}$ La inversión extranjera directa había provenido básicamente de Japón y Estados Unidos, y su destino era la industria automotriz, del hierro, el acero y, aunque muy menor, la de maquila de prendas de vestir (Gobierno del estado de Aguascalientes, 2011b, pp. 23-25).

Las actividades económicas más recurrentes en el estado hacia la fecha señalada incluían la fabricación de automóviles y autopartes, manufacturas eléctricas, equipo electrónico, metalmecánica, alimentos y bebidas. La industria se había especializado en la producción de componentes con un uso intensivo de nuevas tecnologías, y los sectores con posibilidades de innovar eran los de las TIC, el automotriz, el agroindustrial y el textil, aunque este último requería modernización.

En el mundo laboral, los trabajadores se concentraban mayoritariamente en el sector de servicios y en las manufacturas y la construcción, pues la industria automotriz había sufrido el impacto de la crisis global del 2008, representado en pérdida de empleos, lo que llevó a que las personas con menores calificaciones laborales contaran con trabajo con

II. Respecto a este problema, se tomaron medidas vía el Proyecto de Creación del Consorcio de Innovación y Transferencia Tecnológica para el Desarrollo Agroalimentario del Estado de Aguascalientes (FOMIX AGs-2016-02-278272), cuya convocatoria fue ganada por el Centro de Investigación y Asistencia en Tecnología y Diseño del Estado de Jalisco (CIATEJ). 
baja remuneración y a que el desempleo se localizara sobre todo entre aquellos con estudios universitarios.

Ante este panorama, se volvía importante poner en marcha estrategias para incrementar el número de empleos mejor remunerados, aunque se hizo evidente que el interés estaba más bien en atender la demanda de mano de obra para el sector automotriz, pese a que la posibilidad del mismo de generar empleos bien pagados fue mínima.

Aunque la fortaleza de Aguascalientes había sido contar con una economía muy diversificada, las acciones del sexenio 2010-2016 se enfocaron particularmente en el sector automotriz, considerado clave al generar poco más de un tercio del PIB estatal (Gobierno del estado de Aguascalientes, 2015).

Así, en 2012 inició la construcción del complejo Nissan A2, ${ }^{12}$ cerca del poblado de Peñuelas, en un área de 480 ha -más del doble de las que tenía el primer complejo de dicha empresa- ${ }^{13}$ La planta, inaugurada a fines de 2013, significó una inversión de USD 2000 millones (Gobierno del estado de Aguascalientes, 2015). Previamente, en la misma zona había iniciado la construcción del Parque Industrial de Logística Automotriz (PILA), en el que se instalaron TIER $1,{ }^{14}$ proveedoras del sector automotriz (Carbajal Súarez, Almonte, y Mejía Reyes, 2016, pp. 50-51).

La atracción de inversión extranjera especializada al estado requirió desarrollar corredores industriales, consolidar los que ya existían, darle mantenimiento a la infraes-

12. Carlos Lozano de la Torre, ahora como gobernador de la entidad, recibía la llegada de la Nissan A2, como lo había hecho más de tres décadas atrás, en 1982, entonces como secretario de Promoción Industrial y Comercial y como importante promotor de la industria automotriz, esto último durante el sexenio de Rodolfo Landeros Gallegos.

13. En su primera fase, producía 175000 vehículos, en un centro de manufactura de 220000 metros cuadrados (Gobierno del estado de Aguascalientes, 20 I5).

I4.TIER I es el proveedor cuya red está libre de tránsito, es decir, el que está en relación directa con la armadora. En este caso, se instalaron en esa zona varias TIERI.

Sociedad No.77 
tructura carretera y a los parques industriales, y desarrollar cadenas productivas y de comercialización (Gobierno del estado de Aguascalientes, 2015, pp. 14-19).

Con el esfuerzo focalizado en la industria automotriz, como ya se dijo, se hizo una promoción de inversión extranjera especializada para ampliar la cadena de suministro de la misma, lo que permitió asentar en Aguascalientes a empresas japonesas como Exedy-Dynaxy Jarco Limited, UniPress, Yokohama, Goysyu y Neturen, entre otras, que en un corto plazo iniciaron operaciones.

También se construyó un ferropuerto, en 2014, para embarcar y mover la producción de las plantas Nissan A1 y A2. En 2015, inició la construcción de la tercera planta COMPAS, en alianza Nissan/Daimler, cuya apertura se planeó para el 2017. Sin duda, Carlos Lozano de la Torre había previsto que Aguascalientes fuese líder en la producción automotriz (Gobierno del estado de Aguascalientes, 2015).

Por otro lado, se promovió la inversión alemana e italiana, y en 2015 se firmó una carta de intención para la cooperación entre clusters automotrices entre la Asociación Industrial del Estado de Baden (Alemania) y los estados mexicanos de Guanajuato, Jalisco, Querétaro y Aguascalientes, la cual dio lugar al cluster automotriz GIRAA (Gobierno del estado de Aguascalientes, 2015, p. 20).

Todas estas acciones impulsaron lentamente el crecimiento de la entidad, e incluso el informe del IMCO apuntó en 2016 que los estados participantes en el acuerdo con Baden eran los que más habían crecido en el último lustro, con porcentajes entre 5.4 y 6.3\% (Instituto Tecnológico y de Estudios Superiores de Monterrey, 2016). Por otro lado, Aguascalientes fue uno de los estados con mayores exportaciones sobre porcentaje del PIB estatal, con un crecimiento promedio de 6.4\% (Instituto Tecnológico y de Estudios Superiores de Monterrey, 2016, pp. 14 y 17). 
De acuerdo con los lineamientos establecidos en el Plan Sexenal de Gobierno 2010-2016, se incrementó en Aguascalientes el presupuesto destinado a la ciencia y la tecnología, vía FOMIX. Estos fondos, diseñados sobre un esquema de colaboración, se han orientado a contribuir al desarrollo de las regiones donde han sido aplicados y están enlazados con los proyectos estratégicos incluidos en los planes estatales de desarrollo, vinculados con la demanda de conocimiento que se define a nivel local. ${ }^{15}$

Desde 2002 y hasta 2016, se habían entregado a Aguascalientes MXN 383810245.00 provenientes de FOMIX, en concreto a IES, CPI, asociaciones y sociedades con fines de lucro, para un total de noventa y un proyectos, seis de los cuales fueron cerrados y otros seis cancelados (Consejo Nacional de Ciencia y Tecnología, 2017a). Entre 2011 y 2016 , se pusieron en marcha veinticuatro proyectos enfocados sobre todo al fortalecimiento de la infraestructura, la investigación científica y el desarrollo tecnológico de la entidad, por un monto total de mxN 259124030.00 (Tabla 1), lo que representó el $67.52 \%$ del total erogado por el fondo desde su apertura.

15. Los fondos emiten convocatorias en cinco modalidades: investigación científica, desarrollo tecnológico, formación de recursos humanos y consolidación de redes de investigación, creación y fortalecimiento de infraestructura, y difusión y divulgación (Consejo Nacional de Ciencia y Tecnología, 2017a).

Sociedad No.77 
Tabla 1. Proyectos e instituciones que obtuvieron financiamiento FOMIX en Aguascalientes (2011-2016)

\begin{tabular}{|c|c|c|}
\hline Nombre del proyecto & $\begin{array}{l}\text { Institución } \\
\text { responsable }\end{array}$ & $\begin{array}{c}\text { Monto del } \\
\text { proyecto }\end{array}$ \\
\hline $\begin{array}{l}\text { Diseño y puesta en marcha de talleres } \\
\text { y programas educativos en las } \\
\text { instalaciones del Centro de Ciencia } \\
\text { y Tecnología Descubre de la ciudad } \\
\text { de Aguascalientes, que contribuyan a } \\
\text { la alfabetización y desarrollo de una } \\
\text { cultura digital en la entidad. }\end{array}$ & $\begin{array}{l}\text { Sistemática } \\
\text { Grupo } \\
\text { Consultor }\end{array}$ & 13900000.00 \\
\hline $\begin{array}{l}\text { Intervención integral para reducir } \\
\text { el déficit digital en el estado de } \\
\text { Aguascalientes. }\end{array}$ & UAA & 5834712.00 \\
\hline $\begin{array}{l}\text { Degradación foto-catalítica de } \\
\text { hormonas esteroideas y antibióticos } \\
\text { mediada por nano-catalizadores de } \\
\text { dióxido de titanio dopado con hierro. }\end{array}$ & UAA & 450000.00 \\
\hline $\begin{array}{l}\text { Estrategias de control biológico de } \\
\text { las principales plagas de la vid en } \\
\text { Aguascalientes. }\end{array}$ & UAA & 253490.00 \\
\hline $\begin{array}{l}\text { Impacto de la innovación y la } \\
\text { tecnología en el crecimiento y } \\
\text { competitividad de las pymes de } \\
\text { sectores estratégicos del estado de } \\
\text { Aguascalientes. }\end{array}$ & UAA & 595000.00 \\
\hline $\begin{array}{l}\text { Eficiencia del uso de agua y nutrientes } \\
\text { en los sistemas de producción de leche } \\
\text { en Aguascalientes. }\end{array}$ & INIFAP & 588700.00 \\
\hline $\begin{array}{l}\text { Modelo de intervención para la } \\
\text { reconversión tecnológica y la obtención } \\
\text { de mejoras competitivas en la } \\
\text { micro, pequeña y mediana empresa } \\
\text { manufacturera de Aguascalientes. }\end{array}$ & $\begin{array}{l}\text { Universidad } \\
\text { Politécnica de } \\
\text { Aguascalientes } \\
\text { (UPA) }\end{array}$ & 6000000.00 \\
\hline $\begin{array}{l}\text { Apoyo al posgrado. Fondo mixto de } \\
\text { fomento a la investigación científica y } \\
\text { tecnológica. }\end{array}$ & UPA & 2000000.00 \\
\hline
\end{tabular}

\section{6}


Colaboración entre centros públicos de investigación para el desarrollo regional: un análisis de caso en Aguascalientes, México

\begin{tabular}{|c|c|c|}
\hline Nombre del proyecto & $\begin{array}{l}\text { Institución } \\
\text { responsable }\end{array}$ & $\begin{array}{l}\text { Monto del } \\
\text { proyecto }\end{array}$ \\
\hline $\begin{array}{l}\text { Identificación de las oportunidades } \\
\text { de integración de la red de valor de la } \\
\text { guayaba en Aguascalientes. }\end{array}$ & INIFAP & 384000.00 \\
\hline $\begin{array}{l}\text { Remoción de fluoruros del agua } \\
\text { del municipio de Aguascalientes } \\
\text { empleando filtros caseros y } \\
\text { determinación de los parámetros } \\
\text { fisicoquímicos del agua tratada. }\end{array}$ & $\begin{array}{l}\text { Instituto } \\
\text { Tecnológico de } \\
\text { Aguascalientes } \\
\text { (ITA) }\end{array}$ & 400000.00 \\
\hline $\begin{array}{l}\text { Síntesis de absorbentes para la } \\
\text { remoción de arsénico del agua } \\
\text { empleando residuos textiles. }\end{array}$ & ITA & 378000.00 \\
\hline $\begin{array}{l}\text { Desarrollo de una aplicación móvil } \\
\text { para datos meteorológicos como } \\
\text { herramienta de apoyo de los sectores } \\
\text { productivos en Aguascalientes. }\end{array}$ & INIFAP & 370000.00 \\
\hline $\begin{array}{l}\text { Modelo para la generación y } \\
\text { consolidación de capital humano } \\
\text { estratégico que responda a los } \\
\text { requerimientos de la industria } \\
\text { automotriz del estado de } \\
\text { Aguascalientes. }\end{array}$ & ITESM & 2998444.00 \\
\hline $\begin{array}{l}\text { Desarrollo y puesta en marcha de un } \\
\text { centro especializado en alfabetización } \\
\text { y certificación de habilidades. }\end{array}$ & INFOTEC & 9948251.00 \\
\hline $\begin{array}{l}\text { Laboratorio de alta especialidad en } \\
\text { ingeniería estadística con enfoque al } \\
\text { desarrollo e innovación de la industria } \\
\text { automotriz y de autopartes del estado } \\
\text { de Aguascalientes. }\end{array}$ & CIMAT & 15000000.00 \\
\hline $\begin{array}{l}\text { Laboratorio nacional de } \\
\text { geointeligencia con sede en } \\
\text { Aguascalientes del Centro de } \\
\text { Investigación en Geografía y } \\
\text { Geomática Ing. Jorge L. Tamayo, A. } \\
\text { c.-Conacyt.* }\end{array}$ & Centro Geo & 16000000.00 \\
\hline $\begin{array}{l}\text { Cultura y educación itinerante para la } \\
\text { difusión de la ciencia y la tecnología en } \\
\text { el estado de Aguascalientes.* }\end{array}$ & $\begin{array}{l}\text { Fundación } \\
\text { Mex-Eu para la } \\
\text { Ciencia }\end{array}$ & 10000000.00 \\
\hline
\end{tabular}

Sociedad No.77 


\begin{tabular}{|c|c|c|}
\hline Nombre del proyecto & $\begin{array}{l}\text { Institución } \\
\text { responsable }\end{array}$ & $\begin{array}{l}\text { Monto del } \\
\text { proyecto }\end{array}$ \\
\hline $\begin{array}{l}\text { La robótica y las energías renovables: } \\
\text { experiencias lúdicas de aprendizaje.* }\end{array}$ & $\begin{array}{l}\text { Universidad } \\
\text { Tecnológica de } \\
\text { Aguascalientes } \\
\text { (UTA) }\end{array}$ & 9987300.00 \\
\hline $\begin{array}{l}\text { Aplicación de métodos biotecnológicos } \\
\text { para la propagación y uso racional } \\
\text { de plantas adaptadas a la baja } \\
\text { disponibilidad de agua.* }\end{array}$ & UAA & 4189133.00 \\
\hline $\begin{array}{l}\text { Mapa de riesgos y sistemas de } \\
\text { información para fortalecer la } \\
\text { seguridad y capacidad de respuesta en } \\
\text { el estado de Aguascalientes.* }\end{array}$ & Centro Geo & 8450000.00 \\
\hline $\begin{array}{l}\text { Creación del Centro de Innovación } \\
\text { y Transferencia Tecnológica de } \\
\text { Aguascalientes para el Sector } \\
\text { Automotriz (CITTAA).* }\end{array}$ & $\mathrm{CIO}$ & 74000000.00 \\
\hline $\begin{array}{l}\text { Modelo de intervención para el } \\
\text { fortalecimiento de la competitividad } \\
\text { en la cadena de suministro del sector } \\
\text { automotriz y de autopartes del estado } \\
\text { de Aguascalientes.* }\end{array}$ & CIATEQ & 12400000.00 \\
\hline $\begin{array}{l}\text { Fortalecimiento de la infraestructura } \\
\text { del laboratorio de innovación } \\
\text { y caracterización de sistemas } \\
\text { termosolares y fotovoltaicos.* }\end{array}$ & CIO & 10000000.00 \\
\hline $\begin{array}{l}\text { Creación del consorcio de innovación } \\
\text { y transferencia tecnológica para el } \\
\text { desarrollo agroalimentario del estado } \\
\text { de Aguascalientes.* }\end{array}$ & $\begin{array}{l}\text { Centro de } \\
\text { Investigación } \\
\text { y Asistencia } \\
\text { en Tecnología } \\
\text { y Diseño del } \\
\text { Estado de } \\
\text { Jalisco (CIATEJ) }\end{array}$ & 54997000.00 \\
\hline
\end{tabular}

Total de fondos destinados

259124030.00

*Proyectos en desarrollo.

Fuente: Consejo Nacional de Ciencia y Tecnología (2019). 
En la Tabla 1, se observa el tipo de necesidades planteadas en las distintas convocatorias de FOMIX. Para 2011, desde el IDSCEA se atendió la promoción de una cultura digital entre la población con miras a disminuir la brecha existente al respecto, así como mejorar la competitividad en las micro y pequeñas empresas del sector manufacturero. A partir de 2012, acorde con el Plan Sexenal de Gobierno, las demandas se enfocaron a la industria automotriz mediante la generación y preparación del capital humano que requería ese sector. Además, la inversión de la ensambladora Nissan había detonado que las grandes empresas, las TIER1, requirieran programas para el desarrollo de proveedores, por lo que se pensó que las empresas locales podían contar con los requisitos de calidad que estas demandaban (cuyo cumplimiento se impulsó mediante la convocatoria FOMIX 2014-02), lo que representaba un reto.

Entonces, el desarrollo de ciertos rubros industriales requirió ampliar el espectro de los apoyos y fomentar que las empresas locales tuvieran mejores prácticas de producción mediante procesos de innovación y calidad, de modo que pudieran posicionarse entre las grandes cadenas nacionales e internacionales.

En 2014, con miras a esto, se generaron dos demandas más, una para contar con laboratorios de alta especialidad en ingeniería, y otra para un centro especializado en alfabetización y certificación de habilidades. Para 2015, se convocó a la creación del cITTAA, cuya bolsa para el proyecto inicial, de setenta y cuatro millones de pesos, representó casi el $20 \%$ del total destinado al fondo desde su apertura (FOMIX 2015-03). Esto permite apreciar la relevancia del proyecto, considerado estratégico.

En el mismo orden de ideas, en 2016, se planteó la necesidad de fortalecer la cadena de suministro del sector automotriz mediante otra convocatoria (FOMIX 2016-01). 
Es importante mencionar que el sector agroalimentario también recibió una atención relevante en el mismo año.

La finalidad del CITTAA era que la entidad contara con un centro con la infraestructura tecnológica y recursos humanos que, mediante un modelo asociativo, articulara las capacidades de distintos CPI en un ecosistema de innovación y emprendimiento, y que generara soluciones tecnológicas integrales para los sectores automotrices, de autopartes y electrónicos, para hacer empresas más competitivas.

El centro también buscaba atraer inversiones productivas que contribuyeran al desarrollo económico y social de la entidad y detonar una cadena local de proveeduría. Para 2015, la entidad contaba con ciento setenta y tres empresas del sector automotriz tipo tractor no nacionales, lo que generaba la necesidad de fortalecer la cadena de suministro y las relaciones con dichas empresas (propósito del Fomix 2015-03).

La ejecución del proyecto se planteó a veinticuatro meses, y los organizadores de la convocatoria fueron el IDSCEA y la SEDEC. La primera convocatoria, declarada desierta, se emitió en 2015, y la segunda en febrero de 2016. Los resultados de esta última se dieron a conocer en mayo del mismo año, con el cIo como representante de la propuesta ganadora.

El CIO, que fungiría como responsable, contaría con la colaboración del Instituto Nacional de Astrofísica, Óptica y Electrónica (INAOE), el CIATEQ, la Corporación Mexicana de Investigación en Materiales (COMIMSA), el Centro de Investigación en Química Aplicada (CIQA), el Centro de Ingeniería y Desarrollo Industrial (CIDESI), el Centro de Investigación y Desarrollo Tecnológico (CIDETEQ), el Centro de Investigación en Materiales Avanzados (CIMAV), el Centro de Tecnología Avanzada (CIATEC), INFotec, CIMAT y el Instituto Potosino de Investigación Científica y Tecnológica (IPICYT), un total de doce CPI enfocados en atender la demanda que el proyecto 
buscaba satisfacer. El convenio fue firmado y el proyecto comenzó a unos meses del cambio de Gobierno en el estado.

En el mismo 2016, se emitió la convocatoria del mismo fondo orientada a crear una cadena de proveeduría, ya señalada, para el mismo sector atendido por ciTTAA. En dicha convocatoria, el CIATEQ presentó la propuesta ganadora, con un esquema también de colaboración donde se integraron el CIMAT y el INFOTEC.

Reunir los elementos necesarios para definir y plantear la creación del CITTAA le había llevado prácticamente todo el sexenio a la administración estatal, lo que traslapó estos esfuerzos con la recién publicada Agenda de Innovación de la Región Centro/Norte $2014,{ }^{16}$ que planteó como áreas de especialización de la zona a la industria automotriz y de autopartes.

Al nuevo Gobierno estatal, panista, le tocaría dar seguimiento al proyecto en un contexto local, nacional e internacional complicado, cuando un cambio en la Presidencia de Estados Unidos generó una actitud en la política oficial de dicho país contraria al TLCAN. Sin embargo, los equipos de economía de los tres países firmantes del TLCAN iniciaron negociaciones y el 30 de mayo de 2019, en el portal del Gobierno de México, se informó que el Ejecutivo federal entregaría al Senado de la República los textos del Tratado entre los Estados Unidos Mexicanos, los Estados Unidos de América y Canadá (T-MEC), para su consideración, análisis $y$ eventual aprobación (Gobierno de México, 2019). Cabe señalar que el T-MEC es la reconfiguración del TLCAN.

16. En dicha agenda, del Conacyt, la región estuvo integrada por Aguascalientes, Guanajuato, Querétaro y San Luis Potosí. 
5. Percepciones y reflexiones de los distintos actores participantes en la creación del centro/consorcio de investigación

En este apartado, se retoman y analizan las reflexiones y consideraciones que tienen los tres actores involucrados en la construcción y puesta en marcha del CITTAA, es decir, el sector académico, el estatal y el empresariado.

El CITTAA, liderado por el cio, continuó el desarrollo del proyecto en conjunto con los otros once CPI, ya señalados, lo que permitió que se concentraran en el proyecto las capacidades de cada centro. Como se comentó, esta forma de trabajo conjunta, los consorcios de investigación, ${ }^{17}$ formó parte substancial de la política científica del Conacyt.

El proyecto, planteado en tres fases, incluyó un diagnóstico de necesidades del sector, un plan de negocio y un modelo de operación. También, amparó la construcción de tres edificios con espacios para laboratorios de manufactura avanzada y el desarrollo de materiales y de electrónica - esto es, control, visión y robótica-, con los equipos necesarios para atender las demandas del sector mediante el desarrollo de proyectos, transferencia de tecnologías y un catálogo disponible de posibilidades de atención a necesidades. Del mismo modo, el proyecto incluyó la generación de convenios con las IEs locales y con el empresariado del sector automotriz, por lo que para su operación se articularon un Consejo Consultivo y un gerente, ${ }^{18}$ de acuerdo con los lineamientos de gobernanza de los consorcios de investigación (Consejo Nacional de Ciencia y Tecnología, 2017b).

17. El CITTAA, cuya primera inicial indicaba centro, para el Conacyt formó parte de su política de investigación: la creación de consorcios de investigación. Así, los empresarios y funcionarios del Gobierno estatal, por lo general, se referían a este como centro, en tanto que para el Conacyt era consorcio.

18. Para todas las personas entrevistadas en el presente trabajo, se han empleado seudónimos.

\section{2}


De acuerdo con los directivos de los CPI, para el desarrollo del CITTAA se ponía en marcha una propuesta de trabajo novedosa, consorciada, donde se contaría con la infraestructura necesaria para el desarrollo de proyectos y solución de problemas de una manera innovadora. Por lo que toca al empresariado local del sector, este se mostró interesado en conocer las capacidades que tenían los CPI para trabajar con ellos en la exposición de sus problemáticas y generar propuestas de solución. Esta actitud positiva frente a los CPI fue sin duda importante, pues la agenda de innovación enfatizaba la importancia que tenía la participación conjunta de los tres actores para el desarrollo regional, es decir, de la triple hélice para el caso del CITTAA.

A fines del 2016, aun con la toma de posesión del nuevo Gobierno, los acuerdos previos y los compromisos formulados continuaron su marcha, aunque se registraron algunos retrasos asociados a entregas, recepciones de documentación y el inicio de la nueva administración. En el entonces nuevo Plan Estatal de Desarrollo 2016-2022 (PED), integrado por cinco ejes, el tema económico ocupó el cuarto lugar, y el objetivo al respecto fue configurar un nuevo mercado laboral y económico para atraer nuevas inversiones, empujar la creación de nuevas empresas locales y fortalecer las existentes, es decir, diversificar.

El enfoque del nuevo Gobierno sería entonces no sólo empujar al sector automotriz y de autopartes, sino fortalecer la industria electrónica y de las TIC e incursionar en otras nuevas, como la aeroespacial, lo que refrendaba la necesidad de incorporar proveedores locales en las cadenas globales, así como mejorar la competitividad de las micro y pequeñas empresas locales (Gobierno del estado de Aguascalientes, 2017).

Los funcionarios entrevistados para esta investigación en el marco de su colaboración en el proyecto del cITTAA hicieron hincapié en la importancia de la contribución del Gobierno 
estatal al avance y fortalecimiento de la ciencia y la tecnología, así como en su impulso al proceso de innovación.

Desde la perspectiva del IDSCEA, la participación del Gobierno estatal abonaba a la creación de fuentes de trabajo con un mayor valor agregado, lo que había sido una demanda sistemática de la población de la entidad. La demanda concreta que generó la creación del CITTAA se enfocaba en las industrias automotriz y de autopartes y electrónica y de las TIC, por lo que "en este sentido era flexible, pues no se concentraba en un solo sector" (Ugarte, 2017).

Como usuario del proyecto, el interés del Gobierno era promover una cadena de proveeduría para hacer escalar a las empresas locales, de modo que innovaran en sus procesos y productos. Esto requería de capacitación y atención al fortalecimiento de las empresas locales, por lo que el CITTAA ya había "empezado a empujar otro proyecto de apoyo, liderado por CIATEQ, para impulsar el desarrollo de proveedores, enfocado a las pequeñas y medianas empresas, que se percibió como uno de los primeros logros" (Ugarte, 2017).

Con relación a los retos que enfrenta el centro/consorcio en el futuro, los actores entrevistados también hicieron énfasis en el tema de la integración, concretamente en que se lograra trabajar con empresas de todos los tamaños, e igualmente importante les pareció lograr el trabajo intercentros, como proponía el esquema original, aun siendo visto como algo complejo.

También, los usuarios del proyecto perciben a los CPI como instituciones con una gran capacidad de coordinación y de generación de acuerdos, cuyos retrasos han sido menores, y que han podido concluir la primera etapa de la operación. Además, desde los CPI, como parte del ejercicio de vinculación, se inició el proceso de tender puentes con IES asentadas en Aguascalientes (Ugarte, 2017).

En el caso de los empresarios entrevistados que tuvieron relación con algún CPI, vía pruebas de medición o solicitud 
de otros servicios, estos percibían al CITTAA como un proyecto centrado en la industria automotriz y de autopartes, "ya que el Gobierno saliente apoyó proactivamente sólo a este sector" (Unzaga, 2017).

Algunos empresarios se han dado a la tarea de informarse y conocer específicamente los objetivos del centro/consorcio; otros han participado en las distintas reuniones convocadas para la elaboración de un diagnóstico que señale las necesidades del empresariado local de los sectores involucrados, y a las cuales también ha acudido personal de las universidades y los CPI involucrados. Desde luego, otros empresarios no han tenido relación alguna con el centro/consorcio, aun cuando por el tipo de actividades económicas que realizan esto debió haber sucedido.

Para otros de los empresarios, resulta relevante contar con laboratorios para realizar pruebas que se requieren, de ahí que la creación del CITTAA se considere importante. Sin embargo, albergan dudas respecto a su funcionamiento basadas en experiencias previas, puesto que cuando han tenido que acercarse a los CPI han encontrado que sus tiempos de respuesta son lentos, ya que no trabajan al ritmo de la industria (Uribe, 2017).

La deficiencia señalada se explica porque aunque el equipamiento de los CPI es excelente, el listado de procedimientos burocráticos que se debe cumplir para emitir una orden de servicio se extiende sobremanera y contrasta con lo que ofrecen las empresas privadas, donde el procedimiento es casi inmediato. Esto se suma a la multiplicidad de oficios que deben firmar los directivos de los cPI, labor que les toma tiempo y convierte el proceso en poco dinámico. Desde esta perspectiva, los empresarios esperan que el CITTAA elabore nuevos procedimientos que hagan expedita la solución de los problemas y la oferta de servicios que demanden (Urquiaga, 2017).

Sociedad No.77 
También, los empresarios externaron preocupación con respecto a los costos de los servicios ofrecidos por los CPI, al considerar que no son competitivos con respecto a las empresas que los ofrecen. En un contexto en que tienen opciones, los empresarios optan por la más económica. Este tema fue retomado por varios empresarios entrevistados, lo que señala la pertinencia de su discusión.

Otro de los puntos discutidos por los empresarios se refirió al desconocimiento que estos tienen del abanico de servicios que ofrecen los CPI asentados en Aguascalientes, y a que también desconocen si estos se enfocan a problemáticas similares o distintas entre sí, o si atienden el mismo tipo de problemas pero con capacidades diferentes, o si prestan diferentes servicios. Con relación al cITTAA, algunos empresarios mencionaron tener conocimiento de que estaría integrado por varios CPI, pero poco o nada saben sobre las funciones que tendría para la zona y el sector.

Los CPI son percibidos por los empresarios como entidades ajenas y distantes, lo que sin duda es un asunto problemático y urgente por atender, puesto que el sector empresarial, junto con los usuarios gubernamentales, es uno de los actores claves para estos centros. El poco o nulo conocimiento de lo que son y hacen los CPI y de las actividades que realizan se extiende también a las IES, básicamente porque los centros no han hecho la tarea de comunicar a la sociedad y a los distintos sectores lo que hacen. Si partimos de la premisa del Conacyt -como cabeza del sector-de que los cPI se enfocan en la atención de problemas nacionales, lo menos que puede esperarse es que sean ampliamente conocidos.

Los empresarios también manifestaron estar preocupados por la forma en que el CITTAA resolverá el tema de quién del proceso debe atender qué y en qué momento, esto por su integración a partir de una docena de CPI. Su inquietud tenía que ver, por tanto, con que la participación de las partes se resolviera, de modo que al acercarse ellos al cITTAA con una

\section{6}


problemática específica obtuvieran una respuesta expedita. En ese sentido, esperaban claridad sobre la manera en que atendería a los clientes, y también sobre cuál o cuáles CPI lo harían, con un tiempo de respuesta razonable y un costo competitivo. También, desconocían si el centro/consorcio trabajaría con empresarios de la localidad y la región para apoyar el desarrollo de la zona, o solamente se asentaría en esta, lo que consideraban inadecuado al ser inversión de la entidad.

Con relación al CITTAA, se encontró que los empresarios del sector automotriz y de autopartes desconocían la manera en que avanzaba el proyecto, aun cuando estos mantenían relaciones de trabajo con algunos de los doce cPI, lo que es un indicador de fallas en la comunicación por parte de los participantes. Estas fallas también pueden ser el reflejo de las complicaciones esperables cuando se pone en ejercicio un nuevo modelo de trabajo, y de que los CPI estaban preocupados por demandar apoyo del Gobierno estatal y esto hacía que el sector empresarial se sintiera desatendido. Es decir, que al menos en ese momento, los CPI vinculados al CITTAA brindaban soluciones a problemas que las empresas les presentaban, pero aún de manera individual y no de forma consorciada (Urrutia, 2017).

Los empresarios de la industria electrónica, por su parte, hicieron énfasis en que este ramo está incluido en el proyecto, como se puede constatar en la convocatoria emitida. Por esta razón, esperaban que el CITTAA no se convirtiera en una ventanilla única, es decir, que sólo atendiera al sector automotriz y de autopartes. También, destacaron que la parte rectora del CITTAA no debía estar solamente en los CPI, sino que era necesario que se operara también en un modelo de administración tripartita en el que participaran la empresa privada, el Gobierno y la academia (Valverde, 2017), concretamente, que se ajustara al modelo de la triple hélice. Un punto que llamó la atención es que los empre- 
sarios del sector automotriz y la electrónica desconocían que el centro se había convertido en un consorcio, pues no habían sido informados al respecto.

Entre las IEs de la entidad que integran el Consejo de Vinculación de las Instituciones de Educación Superior en el estado de Aguascalientes y el consejo rector del CITTAA existe buena relación, aunque muy poca comunicación, e incluso algunas de las primeras ya firmaron un convenio marco con el segundo, con el que esperan concretar puntos y vínculos específicos.

Como instituciones formadoras, las IES involucradas con el CITTAA tienen interés en que sus egresados accedan a estancias en el futuro centro/consorcio, lo que fortalecerá sus conocimientos y formación pues les permitirá contar con experiencia en el sector empresarial (Vázquez, 2017). También, les interesa converger con el centro/consorcio en intereses y acciones encaminadas a lograr beneficios para la entidad y hacer vínculos para proyectos específicos, lo que no sucede en el caso de los CPI asentados en la entidad, que prácticamente no tienen comunicación con otras instituciones, lo que deviene en otro aspecto de atención urgente.

El proyecto del CITTAA inició formalmente en septiembre de 2016 con el reto de integrar a los participantes en una forma de trabajo consorciada para que fuera factible atender las demandas del sector automotriz. Como ya se adelantaba, el cio fungió como líder y administrador de los fondos. El arranque fue lento y resultó complicado lograr acuerdos entre los participantes. Para febrero de 2017, Conacyt emitió los principios básicos de gobernanza de los consorcios, que apuntaban que no había un modelo único de consorcio, sino que la posibilidad era flexible, aunque todos pasarían por las etapas de propuesta, diseño, instalación, operación y consolidación. El documento elaborado por el Conacyt es una breve explicación de lo que debe suceder en cada fase para la gobernanza y administración

\section{8}


de estos nacientes consorcios (Consejo Nacional de Ciencia y Tecnología, 2017b).

Para el líder del proyecto, el CITTAA ha impuesto una nueva forma de trabajo en colaboración, "que ha significado un cambio de paradigma, un cambio de trabajo individual a otro en donde el trabajo es compartido, en donde se requiere que [los actores] se complementen unos a otros" (Venegas, 2017).

En ese sentido, y aunque se han atendido las partes técnica y operativa y se ha definido lo que es viable ofrecer para el sector industrial, resta aún trabajar en lograr acuerdos intercentros, es decir, definir la colaboración entre las instituciones, tema particularmente complejo cuando algunos CPI coinciden en el tipo de problemas que atienden, en su capacidad instalada y en las posibles soluciones que ofrecen.

Antes de profundizar en los CPI como actor clave de la triple hélice, cabe señalar que, con respecto al cITTAA, la fase de propuesta del proyecto, que devino en la integración de los doce CPI en el mismo, antecedió a la fase de diseño, extendida de enero a septiembre de 2017, y que al término del trabajo de la presente investigación no tenía clara su conclusión. Para el caso de este artículo, entonces, en el caso de los CPI, lo que se analiza es esta fase de diseño y sus implicaciones.

Para el líder del proyecto, había claridad acerca de sus retos, de la definición de lo que es un consorcio y de lo que significaba trabajar a partir de esta idea, que incluía desarrollar proyectos con convergencia de los doce CPI, con la aclaración de que del CITTAA no surgiría un nuevo centro (Venegas, 2017).

Para el líder del cIo, es complejo que un conjunto tienda a lograr un objetivo mayor, pues eso implica lograr acuerdos. En la ejecución del proyecto, les ha sido complejo a los CPI coincidir en que, aún en posición de competidores, es necesario llegar a acuerdos plenos con respecto a decisiones. Lentamente, sin embargo, se han superado los obstáculos, 
y el concepto de colaboración ha permeado al menos a nivel institucional. Estas reflexiones llaman la atención por las dificultades que registró, en el caso del CITTAA, la fase de diseño.

Otro de los puntos complicados del proceso había sido la definición de la estructura de gobernanza interna, donde se habían logrado acuerdos como el establecimiento de un Comité Consultivo del Consorcio (CCC), integrado por los directivos de los CPI participantes, de acuerdo con lo establecido en el documento Principios básicos para la gobernanza y administración de los consorcios de investigación de centros públicos del Consejo Nacional de Ciencia y Tecnología (Consejo Nacional de Ciencia y Tecnología, 2017b). También se formó un consejo integrado por las cámaras empresariales de Aguascalientes y el Gobierno del estado, que aun parece no estar arropado por el CIO y que puede dejar ver problemas a futuro si no mejorara la comunicación entre los tres sectores.

Al emitirse la demanda desde fomix, Aguascalientes definió que el destino del fondo sería para la entidad y se extendería a la región, lo que, como se apuntó, no fue del todo bien visto por los empresarios que creían que si el fondo estaba destinado a la entidad el proyecto debía apoyar mayoritariamente a esta; no obstante, incluso, el líder del cıo ha insistido que la actividad del centro se extendería a todo el país. Todo esto deja ver severos problemas de comunicación y colaboración entre sectores, así como dificultades, si se piensa en el modelo de la triple hélice.

Como parte de la definición de la estructura, y como ya se adelantaba, el CCC nombró a un gerente ${ }^{19}$ para la gestión de proyectos el CITTAA. Dicho gerente contaría con un grupo de apoyo. De manera conjunta, el gerente y los responsables técnicos de los CPI, en consorcio, identificarían y decidirían qué centro es óptimo para liderar cada proyecto. El gerente

19. El nombramiento del gerente no fue inmediato, sino que llevó varios meses.

\section{0}


sería también el responsable de la unidad de negocios y reportaría al órgano de gobierno, el ccc, es decir, atendería las demandas de cada director, lo que sin duda no sería un asunto sencillo.

Adicional a esto, el consorcio no tiene una figura que se sustente jurídicamente, sino que se trata de una estructura suave donde se trabaja por acuerdos, firmas de convenios, establecimiento de objetivos, etc., y en la que cada centro tiene entregables específicos. La complejidad que enfrentaba el CITTAA en esta fase de diseño no es menor, y todavía le faltaría un largo proceso para llegar a su operación, ya que, al menos al término de esta investigación, aún se debían solucionar temas como el del espacio físico donde se construiría. Como ya se apuntó, a fines de 2018 estaba en la fase de iniciar la construcción, y aún quedaba pendiente la operación.

\section{Algunas reflexiones finales}

La exposición de una parte del proceso de la creación del CITTAA, en donde se empleó como herramienta analítica el modelo de la triple hélice formulado por Etzkowitz y Leydesdorff (1997), ha permitido exponer las dificultades presentadas desde su inicio, lo que a su vez supone que trabajar en colaboración es un reto necesario de enfrentar. Es decir, resulta evidente que se trataba de una forma de trabajo nueva, y lograrlo ciertamente no se anticipa fácil.

El presente artículo analizó la fase de diseño del proyecto del centro/consorcio, digamos su arranque, y permite vislumbrar un camino difícil cuya ruta será necesario mejorar para que la propuesta resulte en un proyecto exitoso.

No debe olvidarse que el CITTAA se concibió como uno de los proyectos estratégicos del sexenio 2010-2016 del Gobierno de Aguascalientes, planteado en el respectivo PSD. El centro/ consorcio formó parte de las estrategias planteadas por el 
Gobierno estatal, que entonces sostenía como prioritario el impulso a la llamada sociedad del conocimiento como clave para generar procesos de innovación y mejorar la competitividad regional.

$\mathrm{Al}$ menos al término de esta investigación, no sería factible afirmar que el proceso de implementación del centro/ consorcio sería exitoso y habría logrado una buena colaboración entre los tres sectores implicados en él (cPi/academia, Gobierno estatal y empresariado). De lo analizado hasta aquí, es claro que hasta la fase de diseño del proyecto CITTAA, el logro de cada objetivo había requerido nuevos aprendizajes y acuerdos distintos entre las partes involucradas.

Aprendizajes y acuerdos estarían, en principio, enlazados en el tiempo; se trata de acciones secuenciales, aunque también simultáneas. Esta simultaneidad puesta en marcha ha derivado, en lo inmediato, en gasto de tiempo adicional para la solución de los conflictos que surgen, lo que ha ocasionado retrasos en la calendarización. Esto, en un contexto de un nuevo Gobierno estatal, con otra visión del desarrollo regional, también se observa como un reto necesario de enfrentar y resolver.

Este análisis también ha permitido observar lo complejo que resulta impulsar el desarrollo de una región dado el concurso de actores y acuerdos necesarios para ello, que a su vez implican cambios e incertidumbres, eso dejando de lado el panorama regional y la discusión sobre el TLCAN, que habría sido motivo de largas e inacabadas negociaciones que coincidieron con el arranque del citTAA. Asimismo, no debe obviarse la necesidad que tiene este tipo de proyectos de generar mecanismos de comunicación eficientes entre todos los actores participantes, concretamente los de la triple hélice.

En países como Estados Unidos, donde las empresas tienen divisiones completas dedicadas a investigación y desarrollo, ya se tiene experiencia sobre trabajo en colabora- 
ción con las universidades, así como formas de comunicación que han logrado un lenguaje compartido y a través del cual los actores se conocen, tras años de estar en interacción. Todo ello, sin duda, incrementa las posibilidades de que dichas conexiones generen proyectos donde participan los mismos tres sectores vistos en este trabajo (Santos, 2017), es decir, la triple hélice.

Sin embargo, en los países donde las empresas no tienen espacios de investigación y desarrollo, como es el caso de México, y donde tampoco estas están familiarizadas con los CPI y las capacidades que tienen y lo que les ofrecen, el reto que se enfrenta cuando se plantea trabajar en colaboración es mayor para todas las partes, como se ha podido plasmar en este análisis.

Las reflexiones de empresarios revisadas demuestran que generalmente están más acostumbrados a ubicar y adquirir en el mercado las innovaciones existentes para sus empresas. Por tanto, es muy probable que un grupo amplio de ellos nunca recurra a un CPI para solicitar apoyo o establecer mecanismos de colaboración para el desarrollo de innovaciones en la producción o nuevos productos.

Desde luego, lo anterior está enlazado a que, como aquí se ha analizado, tampoco desde estos CPI se ha trabajado para sensibilizar a los profesionales e investigadores sobre la importancia de atender al mundo empresarial y contribuir con ello al fortalecimiento de las regiones donde están insertos. Entonces, hacerlo abonará a desarrollar mejores formas de interacción entre ellos y a que se logren plantear propuestas que efectivamente impulsen procesos de innovación.

Por otra parte, se debe tener presente que estos empresarios van a encontrar más fácil recurrir a sus esquemas tradicionales de compra que involucrarse en uno de colaboración, el cual no entienden y cuyo funcionamiento desconocen. Por esta razón, cuando los estímulos gubernamentales se ponen en práctica, el modelo de la triple hélice resulta 
difícil de operar en el corto plazo, en gran medida por la poca experiencia de los actores en esta forma de trabajo.

Desarrollar propuestas en condiciones donde este esquema no se conoce implica establecer canales de comunicación que lleven a la generación de un lenguaje común, intereses generales compartidos y formatos específicos de colaboración. En ese sentido, la responsabilidad del Gobierno y los CPI es doble: no sólo aquel tiene que poner recursos y estos hacer investigación, sino que también ambos tienen que generar las condiciones para ese diálogo.

Finalmente, con relación a los recursos aportados por el Gobierno, como los Fomix, y en el marco del cumplimiento de responsabilidades de todas las partes involucradas, es importante trabajar en mecanismos de evaluación de los proyectos que pongan énfasis en el cumplimiento de las demandas, y específicamente en los logros que se obtuvieron. A través de las reflexiones de los distintos actores involucrados en el proceso de diseño del citTAA, se observa que los empresarios y los funcionarios del Gobierno de Aguascalientes esperan que los recursos públicos que se ponen a disposición de un proyecto redunden en beneficio directo para la entidad o comunidad. Esto abona a mejores relaciones y formas de trabajo en colaboración que, como se ha expuesto aquí, es necesario lograr.

Bibliografía

Bernal, G. H., y Mungaray Lagarda, A. (20I7). Los índices de competitividad en México. Gestión y política pública, xxv1(enero-junio), 167-2/8. Recuperado de http://www. gestionypoliticapublica.cide.edu/ojscide/index.php/gypp/ article/view/216

Camacho Sandoval, S. (200 I). Aguascalientes: la democracia en ciernes. Aguascalientes: Instituto Federal Electoral-Instituto Cultural de Aguascalientes.

Camacho Sandoval, F. (20I0). Globalización y transformaciones productivas y territoriales de una ciudad media. 
El caso de la zona metropolitana de Aguascalientes. Bibliografía Carta económica regional, 21 , 43-59. doi https://doi. org/I 0.32870/cer.v0il 04.5532

Carbajal Suárez, Y., Almonte, L., y Mejía Reyes, P. (2016). La manufactura y la industria automotriz en cuatro regiones de México. Un análisis de su dinámica de crecimiento, 1980-20 I 4. Economía:teoría y práctica, (45), 39-66. Recuperado de http://www.scielo.org.mx/pdf/etp/n45/0 I 883380-etp-45-00039.pdf

Castells, M. (1999). La era de la información. Volumen I. La sociedad red. México: Siglo XXI.

Consejo Nacional de Ciencia y Tecnología (2017a). Estadísticas FOMIX, 20I 7. Recuperado de https://www.conacyt. gob.mx/index.php/fondos-y-apoyos/fondos-mixtos

Consejo Nacional de Ciencia y Tecnología (2017b). Principios básicos para la gobernanza y administración de los consorcios de investigación de centros públicos del Conacyt. México: Conacyt. Recuperado de https://www.inaoep. $\mathrm{mx} / \sim$ jgob/hjg/20l8/prim/Anexol.pdf

Consejo Nacional de Ciencia y Tecnología (2019). Fondos Mixtos. Proyectos apoyados. Recuperado de https://www. conacyt.gob.mx/index.php/proyectos-apoyados

Díaz Torres, H., y Feria Cruz, M. (2008). El cluster mueblero en Aguascalientes: un análisis de innovación y competitividad empresarial [ponencia presentada en el vi Congreso Internacional de Análisis Organizacional. Perspectivas Multidisciplinarias en Análisis Organizacional: Complejidad, Ambigüedad y Subjetividad]. Unidad Académica de Contaduría y Administración de la Universidad Autónoma de Nayarit, Red Mexicana de Investigadores en Estudios Organizacionales, Universidad Autónoma Metropolitana: Nuevo Vallarta. Recuperado de: http://www.uacya.uan. edu.mx/VI_CIAO/ponencias/I0_intervencion/I0_I5.pdf Etzkowitz, H. (2002). La triple hélice: universidad, industria y Gobierno, implicaciones para las políticas y la evaluación. 
Estocolmo: SISTER. Recuperado de http://www.sivu.edu. $\mathrm{mx} /$ portal/noticias/2009/VinculacionLatriplehelice.pdf Etzkowitz, H., y Leydesdorff, L. (Eds.) (1997). Universities in the Global Knowledge Economy: A Triple Helix of University-Industry-Government Relations. Londres: Cassell.

Etzkowitz, H., y Leydesdorff, L. (2000). The dynamics of innovation: from National Systems and "Mode 2" to a Triple Helix of university-industry-government relations. Research policy, 29, 109-123. doi http://dx.doi. org/I 0.10I6/S0048-7333(99)00055-4

Franco Ruiz Esparza, C.,y Reyes Rodríguez, A. (2005). El aparente absurdo: 60 años de historia del Partido Acción Nacional en Aguascalientes. Aguascalientes: Grupo Impresor.

Gobierno del estado de Aguascalientes (1996). Aguascalientes. Su ventaja competitiva.Aguascalientes: Gobierno del estado de Aguascalientes, Comisión Estatal de Desarrollo Económico.

Gobierno del estado de Aguascalientes (20 I la). Plan Sexenal de Gobierno del Estado 2010-2016. Aguascalientes: Gobierno del estado de Aguascalientes. Recuperado de http://www.aguascalientes.gob.mx/cplap/Docs/PlanSexenal/PlanSexenal.pdf

Gobierno del estado de Aguascalientes (20l l b). Programa Sectorial 2010-2016. Desarrollo económico, estado de Aguascalientes 2010-2016. Recuperado de http://www. aguascalientes.gob.mx/transparencia/informacion/PROGRAMAS/Sector_Desarrollo.pdf

Gobierno del estado deAguascalientes (2015). Quinto informe de Gobierno. Carlos Lozano. Aguascalientes: Gobierno del estado de Aguascalientes. Recuperado de http:// www.aguascalientes.gob.mx/cplap/Docs/Informes_ de_Gobierno/Quinto_Informe_De_Gobierno_20I5/ DOCUMENTO\%20EJECUTIVO_5TO\%20INFORME.pdf Gobierno del estado de Aguascalientes (2017). Plan Estatal de Desarrollo 2016-2022. Aguascalientes: Gobierno del

\section{6}


estado de Aguascalientes. Recuperado de http://www. aguascalientes.gob.mx/cplap/Docs/PED/PED_Aguascalientes2016_2022.pdf

Gobierno de México (20/9). Recuperado de https://www. gob.mx/se/articulos/inicia-el-proceso-de-aprobaciondel-t-mec-en-mexico-202047? idiom=es

González de la Fe, T. (2009). El modelo de la triple hélice de relaciones universidad, industria y Gobierno: un análisis crítico. ARBOR. Ciencia, pensamiento y cultura,

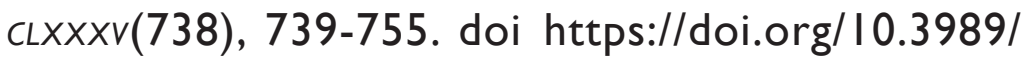
arbor.2009.738n 1049 .

Instituto Mexicano de la Competitividad (2012). ¿Dónde quedó la bolita? Del federalismo de la recriminación al federalismo de la eficacia, índice de competitividad estatal 20/2. Recuperado de https://imco.org.mx/ indice_de_competitividad_estatal_2012/archivos/libro/ Indice_de_Competitividad_Estatal_20I2.pdf

Medina Torres, L. E., y Hernández Olmo, M. (20I2). El proceso electoral en Aguascalientes. Elección estatal 20 I0. En M. Larrosa Haro, y J. Santiago Castillo (Coords.), Elecciones y partidos políticos en México, 2010 (pp. 3 I I-328). México: Senado de la República, LXI Legislatura, Instituto Belisario Domínguez. Recuperado de http://dcsh.izt.uam.mx/cen_ doc/cede/Anuario_Elecciones_Partidos_Politicos\%20 12010_dividido/elecciones_y_partidos_2010.7-10.pdf

Olivé, L. (2005). La cultura científica y tecnológica en el tránsito a la sociedad del conocimiento. Revista de la educación superior, $x x x i v(4), 49-63$. Recuperado de http://publicaciones.anuies.mx/pdfs/revista/Revista I36_S2A2ES.pdf

Organización para la Cooperación y el Desarrollo Económicos (1999). Managing National Innovation Systems. París: OECD. Recuperado de http://echo.iat.sfu.ca/library/ oecd99_managing_National_IS.pdf

Padilla, L. F., Gutiérrez, C. P., y López, G. J. (20I5). Nueva industria regional en Aguascalientes [ponencia presen- 
tada en el marco del $20^{\circ}$ Encuentro Nacional Sobre el Desarrollo Regional en México]. AMECIDER-CRIM-UNAM:Cuernavaca. Recuperado de http://ru.iiec.unam.mx/2920/l/ Eje5-020-Padilla-Gutierrez-Lopez.pdf

Periódico oficial del estado de Aguascalientes ( 3 I de enero de 20I I). Ley que crea el Instituto para el Desarrollo de la Sociedad del Conocimiento del Estado de Aguascalientes, pp. 2-9. Recuperado de http://eservicios2. aguascalientes.gob.mx/periodicooficial/web/viewer. html?file=../Archivos/974.pdf\#page=2

Salmerón, C. F. I., y Serna, P. M. G. (2000). Historia regional de Aguascalientes. Perfil socioeconómico. México: Limusa, Noriega Editores, CONALEP-SEP.

Santos, M. J. (2017). Entre campesinos y farmers. Productores mexicanos de blueberry en Michigan. Metepec: UNAMISS-UIA.

Stake, R. E. (20/3). Estudios de caso cualitativos. En N. K. Denzin, y S.Yvonna Lincoln (Eds.), Estrategias de investigación. Manual de investigación cualitativa, vol. III (pp. I54197). Naucalpan: Gedisa.

Ugarte (2017). Entrevista personal en su calidad de responsable de entidad usuaria del proyecto en el estado de Aguascalientes [M. G. Serna Pérez, entrevistadora]. Aguascalientes, México.

Unzaga (2017). Entrevista personal en su calidad de empresario y líder de grupo empresarial [M. G. Serna Pérez, entrevistadora]. Aguascalientes, México.

Uribe (2017). Entrevista personal en su calidad de empresario del sector automotriz y de autopartes [M. G. Serna Pérez, entrevistadora]. Aguascalientes, México.

Urquiaga (2017). Entrevista personal en su calidad de empresario del sector automotriz y de autopartes [M. G.Serna Pérez, entrevistadora].Aguascalientes, México. 
Urrutia (20I7). Entrevista personal en su calidad de empreBibliografía sario integrante de cluster [M. G. Serna Pérez, entrevistadora]. Aguascalientes, México.

Valverde (20I7). Entrevista personal en su calidad de empresario de la industria electrónica y de telecomunicaciones [M. G. Serna Pérez, entrevistadora].Aguascalientes, México.

Vázquez (20I7). Entrevista personal en su calidad de directivo de institución de educación superior [M. G. Serna Pérez, entrevistadora].Aguascalientes, México.

Venegas (2017). Entrevista personal en su calidad de líder de centro público de investigación [M. G. Serna Pérez, entrevistadora]. Aguascalientes, México. 